\title{
Research on Operation and Management of Intelligent Teaching System in Colleges and Universities
}

\author{
Lie-sheng HUANG ${ }^{1, a}$, Dan ZHANG $^{2}$, Zi-heng HUANG ${ }^{3}$ \\ ${ }^{1}$ Shandong Technology \& Business University \\ ${ }^{2}$ Shandong Technology \& Business University \\ ${ }^{3}$ Yantai Vocational College of Culture and Tourism \\ ${ }^{a}$ Corresponding author: Lie-sheng HUANG,Email: huangls@163.com
}

\begin{abstract}
ABSTRCT
With the development of information technology and its in-depth application in the field of education, colleges and universities are actively building intelligent teaching system, but there are many problems in the operation and management of the system, and the advantages of the system have not been given full play. By constructing an intelligent platform for operation and management and integrating software and hardware systems, this paper realizes the goals of innovating teaching space, co-building and sharing resources, improving teaching quality and management efficiency, and meets the constantly developing teaching requirements.
\end{abstract}

Keywords: Intelligent teaching, Operation and management, Construction

\section{INTRODUCTION}

Under the background of information technologies development of big data, artificial intelligence, internet of things and AR/VR, national policies advocate the construction of teaching informatization and teaching innovation $^{[1]}$. The intelligent education teaching construction and application research marked by intelligent classroom have promoted the fundamental transformation of colleges and universities from digital learning environment to intelligent learning environment. The intelligent teaching system based on the intelligent classroom is one of the teaching reforms in colleges and universities. The construction of hardware system is in full swing. However, during the construction, most universities only focus on the intellectualization of hardware facilities and environment, unable to get rid of the shackles of traditional thinking and habits, making the intelligent classroom become a different traditional classroom. The characteristics and advantages of intelligent teaching can't be really reflected in the application and management.

\section{ADVANTAGES \& CHARACTERISTICS OF INTELLIGENT TEACHING SYSTEM}

Intelligent teaching system mainly includes teaching hardware, teaching environment, teaching software and management system, etc., which is characterized by deep integration, seamless sharing, open on-demand, green management and big data evaluation support ${ }^{[2]}$. The advantages are mainly reflected in the modernization of educational content, teaching means and teaching methods. By highlighting the role of classroom teaching design and organization, personalized teaching can be realized. By improving teachers' information technology application level, teaching concept can be updated and students' interest and initiative in learning can be motivated. By improving classroom teaching efficiency and effect, classroom teaching reform and innovation can be improved. The application of intelligent teaching system in the whole process of teaching and management accelerates talent training mode and the reform of teaching method.

\section{THE PRESENT STATE OF OPERATION AND MANAGEMENT OF INTELLIGENT TEACHING SYSTEM}

\subsection{Teaching mode needs to be innovated}

At present, most teachers in colleges and universities still take PPT demonstration and their lectures as the main teaching form. The whole process lacks communication and interaction between teachers and 
students, and information can only flow from teachers to students in one direction, rather than form a closed loop. In the whole teaching process, students are always in a passive position to receive knowledge, and their initiative in learning is ignored. Especially in the stage of undergraduate education, courses are becoming more and more diverse, and the content of courses is becoming more and more professional. A single teaching mode is not suitable for teaching of every subject in colleges and universities. The flexibility of teaching forms, the diversity of teaching mode and the stages of teaching link failed to reach the expected goals of the improvement of efficiency and quality. It is imperative to innovate teaching mode and application.

\subsection{Construction of high-quality teaching resources is single}

With the gradual implementation of the policy of building golden courses and first-class disciplines, the regular recording and broadcasting of classes in colleges and universities and the accumulation of high-quality school-based resources have gradually become hot. At present, most of the teaching resources in colleges and universities are recorded in special video-recording classrooms. There are many problems, such as high cost, less quantity, less interaction in courseware video-recording, inconsistent video-recording environment, inconsistent online teaching resources, inconsistent service standards and experience, and so on. The application of intelligent teaching in colleges and universities requires a large number of high-quality teaching resources, which can be stored in the resource library platform of universities to realize online live broadcasting and on-demand broadcasting. It helps to carry out micro-class and MOOC teaching and fully communicate and share high-quality teaching resources across universities ${ }^{[3]}$.

\subsection{The utilization rate of teaching equipment is not high}

With the continuous development of technology and the deepening of education informatization, there are more and more information equipment in the classroom. There exist some problems, such as focusing on technology, ignoring teaching and lacking intelligence. All the equipment forms a simple technological pile, which not only does not bring convenience to the teacher, but makes the learning cost of the teacher become bigger and bigger. Convenient and efficient use of informatization equipment and tools provides better technical support, which is helpful for improving teaching efficiency, creating high-quality courses and accumulating more high-quality resources, it is also the basis for the transformation of teaching mode.

\subsection{Device management is difficult}

With the development of educational technology and the promotion of educational informatization, the number of multimedia classrooms and intelligent classrooms has increased rapidly ${ }^{[4]}$. The types of classroom equipment are increasingly complex. The equipment is easy to wear and tear and difficult to maintain, and the management has become a major problem in colleges and universities. Therefore, how to balance the construction of multimedia classrooms and the later equipment operation and maintenance has become an important consideration in the overall design of intelligent classrooms. A more efficient and easy-to-use centralized management mode is realized by intelligent management means, which makes the visualization, remote, intelligence of the classroom equipment operation and maintenance management become possible.

\subsection{Artificial and inefficient teaching process management}

College teaching is characterized by a large number of students and subjects. Under the current teaching management mode, teaching management personnel have heavy tasks and great responsibilities. The evaluation of teaching effectiveness in colleges and universities still remains in the initial stage of lack of data, information isolation, artificial management and insufficient intelligence. The teaching supervision and lesson evaluation of teachers also need the supervisor to attend lectures in the classroom. The paper version of lesson evaluation records is difficult to help teachers reflect on teaching, and it is difficult to promote and learn excellent teaching cases. The limitation of teaching evaluation results affects the further improvement of teaching management level in colleges and universities.

\subsection{Innovation is Lack of data analysis}

Most of the teachers' classes are still based on in-class teaching, so the teachers paid little attention to the actual participation and progress of the students in the learning process. Colleges and universities have no means and tools to excavate teaching data. It results the teaching quality improvement is lack of guidance and basis under the new era. Innovation is lack of the process data in the teaching process, so it is difficult to get the relationship between them and students' learning behavior rules by analyzing the correlation behavior indicators, let alone guidance and suggestions based on the analysis results. 


\section{CONSTRUCTING OPERATION AND MANAGEMENT PLATFORM OF INTELLIGENT TEACHING SYSTEM}

In view of the present state and problems of the above intelligent teaching system, a reasonable and effective comprehensive platform for operation and management should be established. The modernization of education content, teaching means and teaching methods is promoted through the innovative teaching operation and management system and the internet teaching mode, so the application of information technology level of teachers and students can be improved, teachers' teaching concepts can be updated and teaching methods and effects can be improved ${ }^{[5]}$.

\subsection{Establishing a university-based quality teaching resource center}

Various departments' online teaching resources platform can be integrated, combining with their own teaching resources, teaching process, offline teaching resources, training resources, and all the classrooms' live broadcast and recorded data in universities, based on the existing school teaching system, resources and an APP can be unified.

\subsection{Connecting and integrating the existing related platforms}

The existing educational administration management platform, training management platform, school-enterprise cooperation resources, students' interaction platform, examination administration management platform, equipment management platform and digital campus platform need to be integrated, which takes service teaching as the core to achieve the overall teaching-related service unity.

\subsection{Establishing a comprehensive software and hardware management platform.}

Operation and maintenance management of all teaching-related equipments are unified to support classroom equipment configuration management, so that classroom equipment status can be displayed through 3D visualization. The status of all classrooms can be examined globally for remote management, the platform can provide intelligent scenario switching services for teaching services. Finally, online teaching and offline teaching are seamlessly integrated. All hardware and software equipment will automatically report and analyze the data around the teaching process, which is convenient for the school to carry out online and offline mixed teaching.

\subsection{Building comprehensive teaching service portal}

All classroom teaching-related, practice-related, teaching business, examination business, supervision and evaluation are integrated to build a unified information portal for teaching data center and online teaching, which can carry out online and offline mixed teaching. It ensures that the number of concurrent online students is not lower than the number of existing teachers and students in universities.

\subsection{Building an online exam system}

PC management side, PC students answer side and mobile students answer side of the examination paper management, question bank management, performance management, test management can be provided, ranging from setting the questions, test paper composition, printing to the paper distribution, problem solving, winding, and then to marking the paper, announcing the published scores and statistical analysis of test results. It provides online test package solution in order to achieve online examination anytime and anywhere, personalized examination, teaching and testing separation.

The data of examination platforms of existing departments and training are integrated. The system developer will assist teachers to import and integrate all offline test questions and test resources. All teachers and students will be trained to fulfill the overall digital examination requirements of the universities.

\subsection{Building an online supervision and evaluation platform.}

Leaders, managers of relevant departments and members of the supervision group in universities can learn about the functions and activities related to teaching business through mobile phones or PCS. The data capture and analysis of the teaching activities on the software and hardware platforms can be realized, at the same time, by using means of data excavation, statistics and classification, visual presentation of relevant data is shown, and the support for supervision, evaluation, analysis and decision-making can be provided.

\subsection{Constructing analysis and prediction of teaching big data}

The source data of teaching platform and test platform is highly integrated, data is processed and analyzed, which can provide function modules of a comprehensive analysis including teaching situation, class status analysis, quality analysis, teaching quality analysis, picture analysis and classroom teaching supervision analysis. It can form various visual charts, can forecast the trend of teaching and help the universities' teaching accurately. 


\section{THE OBJECTIVE OF OPERATION AND MANAGEMENT OF INTELLIGENT TEACHING SYSTEM}

\subsection{Innovating intelligent teaching space}

The teaching space is reconstructed to create a lightweight, convenient and all-scene teaching environment. Teaching space is the carrier and basis of innovative classroom teaching mode. Scenario-based layout can be carried out in intelligent teaching space in combination with teaching business. It solves the problems of hardware accumulation and complex software functions in the classroom, which makes the space play a positive role in promoting teaching. It is the supporting condition for realizing teaching and learning reform. It has also become a new concept, a new model and a new trend for schools to promote the development of teaching.

\subsection{Providing classroom teaching experience}

Intelligent teaching interactive functions can provide interaction functions of teaching demonstration, problem sets, barrage, screen sharing, learning classroom and real-time feedback between teachers and students, so the advanced teaching and learning methods such as subject linkage, group discussion, interactive solution, special topic speech and learning evaluation can be realized. Hybrid online and offline classes and immersion teaching environment includes the group discussion type, PBL, flip class type and remote interaction can be built for classroom teaching. On the basis of the discussion and interaction between teachers and students, learning situation of each knowledge points can be guided, analyzed and forecasted.

\subsection{Realizing joint contribution and sharing of resources}

Through the construction of new intelligent classrooms, the time and space restrictions are broken, and cross-campus and cross-curriculum resource exchange cab be realized. While building high-quality university-based resources, excellent resources outside the universities are introduced and a knowledge base of teaching resources will be established.

\subsection{Help improve the quality of teaching}

The warehouse storage data in the teaching process can be set up. By using teaching and learning data excavating analysis technique, the students' actual performance and progress during their participation in the process of learning can be researched. By analyzing behavior correlation index, the mutual relationship and the students' learning behavior rule will be drawn. According to the result of analysis, the students will be provided with guidance and advice. The platform provides data reference for teachers to improve curriculum design, optimize teaching methods and improve existing assessment methods. It provides decision support for administrators to implement management better.

\subsection{Improving the efficiency of teaching management}

The informationization and high efficiency of teaching management can be realized. By comprehensively analyzing the teaching status data such as attendance data and teaching data, mobile class evaluation, teaching patrol and supervision, the efficiency and level of teaching management can be improved.

\section{CONCLUSIONS}

Through the construction of the operation and management platform of the intelligent teaching system, we can realize the informatization of teaching content, the strategization of teaching process, the modernization of teaching means and the network of teaching resources. It plays an important guiding role in improving teachers' teaching ability and level, cultivating students' innovation ability, and has far-reaching significance in improving school management level. Intelligent teaching system is only the foundation and condition, operation and management is the goal and benefit, how to make good use of each subsystem is the most concerned problem in teaching application. With the influence of the reform of teaching ideas and teaching methods, the operation and management of the system need to be improved constantly to meet the constantly developing teaching requirements of colleges and universities.

\section{REFERENCES}

[1] Baidu, The National Medium and Long-term Education Reform and Development Plan Outline (2010-2020), https://baike.baidu.com/item/.

[2] Zhang Zhao-ji, Wang Hao etc., Exploration on The Construction Mode of Intelligent Teaching Platform in Ethnic Colleges and Universities, Xizang Science and Technology, No. 12, 2020, pp.55-56.

[3] Zhang Kai, Yang Zai-ming, Construction and Application of Intelligent Classroom -- A Case study of China University of Mining and Technology, Modern Education Technology, No.10,2018, pp.84.

[4] Yu Qiu-lan, Design and Construction of Intelligent Teaching Environment System Structure, Computer Knowledge and Technology, No.10,2020, pp.108.

[5] Zhuo Zhi Education, Intelligent Teaching Platform, June 11, 2016, https://www.wiclass.net. 